\title{
VIDAS ROUBADAS NO EXERCÍCIO DO TRABALHO
}

\author{
Bernadette Cunha Waldvogel \\ Estatística e Demógrafa, Gerente de Indicadores e Estudos Populacionais da Fundação Seade
}

$\mathrm{O}$ s estudos sobre a saúde do trabalhador, analisando as possíveis implicações entre ambiente de trabalho e ocorrência de agressões à saúde física e mental da população economicamente ativa, vêm tendo interesse crescente como objeto de pesquisas e análises, em vários campos do conhecimento.

Dentre as abordagens que envolvem essa questão, encontra-se a relacionada ao acidente do trabalho. Pelas leis brasileiras, consideram-se acidentes do trabalho aquele que ocorre pelo exercício do trabalho, e, a partir de 1967, também o ocorrido no trajeto entre a residência e o local de trabalho ou no intervalo das refeições, provocando lesão corporal ou perturbação funcional que cause a morte, a perda ou a redução, permanente ou temporária, da capacidade para o trabalho.

De acordo com a legislação brasileira, os acidentes do trabalho podem ser classificados em três categorias: acidente-tipo; doença do trabalho; e acidente de trajeto. Como descreve Segre (1985), "os acidentes-tipo são aqueles que ocorrem no exercício do trabalho, de forma concentrada no espaço e no tempo; as doenças profissionais são aquelas com relação direta e constante entre o trabalho que se exerce e o aparecimento de doenças; os de trajeto são aqueles que ocorrem no momento em que o trabalhador estiver se locomovendo do trabalho para a residência e vice-versa, e nos horários de refeição". A conseqüência mais grave dos acidentes do trabalho é a morte do trabalhador.

Estudos avaliando o padrão e o nível da mortalidade no Estado de São Paulo, nas décadas de 80 e 90, têm demonstrado aumento nas probabilidades específicas de morte para as pessoas nas faixas etárias correspondentes à idade ativa, quando comparadas àquelas verificadas em períodos anteriores (Ferreira e Castiñeira, 1996). A mudança no padrão foi tão expressiva, que o nível de mortalidade da população masculina, nessas idades, retornou ao nível observado em 1950. Dentre as causas de morte que mais contribuíram para o comportamento registrado, encontram-se as causas externas, em cujo grupo incluem-se os acidentes do trabalho. Lucca e Mendes (1993), analisando os acidentes do trabalho fatais ocorridos entre 1979 e 1989, em áreas metropolitanas da região Sudeste do Brasil, consideraram que esta causa de morte "pode ter contribuído com um contingente significativo no total das causas externas".

O presente artigo tem como objetivo principal analisar a mortalidade por acidentes do trabalho, no Município de São Paulo, procurando destacar os diferenciais de riscos de morte para a população trabalhadora contribuinte e não contribuinte do Instituto Nacional de Seguridade Social (INSS). A identificação e a quantificação dos casos fatais de acidentes do trabalho fornecem subsídios para a interpretação desta questão e para a atuação do poder público na elaboração de políticas específicas, que procurem minimizar os riscos fatais a que os trabalhadores são vítimas no exercício de sua profissão.

\section{PRINCIPAIS FONTES DE DADOS SOBRE OS ACIDENTES DO TRABALHO FATAIS}

A grande dificuldade nos estudos relativos à mortalidade por acidentes do trabalho é a inexistência de uma 
base de dados completa e contínua sobre os casos fatais de acidentes do trabalho. Os dados sobre estas mortes são provenientes de registros administrativos, cujas fontes principais são as declarações de óbito e os processos de acidentes do trabalho.

A declaração de óbito constitui o instrumento formal para registrar todas as mortes ocorridas no Brasil. É um documento expedido pelo Ministério da Saúde e segue o mesmo padrão para todo o território nacional. A partir da declaração de óbito assinada por um médico, que atesta a causa da morte, o óbito é registrado no Cartório de Registro Civil. No Estado de São Paulo, os Cartórios de cada município enviam mensalmente as declarações de óbito à Fundação Seade, que processa esta informação e organiza o Sistema de Estatísticas Vitais.

A principal vantagem da declaração de óbito como fonte de dados para os estudos da mortalidade por acidentes do trabalho é a diversidade de informações sobre o trabalhador falecido, como sexo, idade, estado civil, ocupação, município de residência e outras, bem como sobre o tipo de causa externa de morte, além de conter um campo especial para notificar se a morte foi devida ou não a um acidente do trabalho, ou se este fato é ignorado. Outra vantagem é que abrange todos os trabalhadores, independentemente de seu vínculo empregatício (formal ou informal), ou de sua condição de contribuinte ou não do INSS.

A principal desvantagem da declaração de óbito, como fonte de dados para estes estudos, consiste na subnotificação importante do quesito específico sobre a circunstância da morte como resultante de um acidente do trabalho, interferindo na identificação e na quantificação dos casos fatais deste tipo de acidente, além de não detectar maiores detalhes sobre o acidente, como, por exemplo, se o local do acidente foi a empresa, se o acidentado estava ou não a serviço da empresa no momento do acidente, etc.

$O$ processo de acidente do trabalho constitui o processo aberto e liquidado ${ }^{1}$ pelo INSS, por ocasião da entrada, pelos dependentes do segurado, da documentação relativa à ocorrência de uma morte devida a um acidente do trabalho. A partir da Comunicação de Acidente do Trabalho (CAT), formulário expedido pelo INSS e preenchido pela empresa, são abertos os processos de acidente do trabalho para os casos em que se constate a necessidade de uma indenização, ou para os casos fatais.

Esta fonte contém diversas informações sobre o acidentado, como sexo, idade, estado civil, ocupação, município de residência, etc. e sobre as circunstâncias do acidente, como local da ocorrência, o fato de o acidentado estar ou não a serviço da empresa, a data do acidente, entre outras

Entretanto, os dados dos processos de acidentes do trabalho referem-se apenas aos trabalhadores contribuintes do INSS, ficando excluídos aqueles cujos dependentes desconhecem se a morte foi devida a um acidente do trabalho, aqueles cujos dependentes residem em outro estado brasileiro, os trabalhadores rurais, os funcionários públicos e, principalmente, os trabalhadores não contribuintes do INSS.

O sistema de informação sobre acidentes e doenças do trabalho, do INSS, objetiva principalmente o processamento dos benefícios aos acidentados, aos dependentes e àqueles acometidos por doenças do trabalho.

Este sistema apresenta diversas limitações para as análises da mortalidade, pois registra apenas os totais dos casos fatais de acidentes do trabalho, sem nenhuma caracterização destes eventos. Este fato faz com que a construção de um banco de dados detalhados sobre os casos fatais só seja possível por intermédio de um levantamento específico, nas agências e postos do INSS espalhados em todo o território nacional.

\section{METODOLOGIA DE COLETA E DE CONSTRUÇÃO DO BANCO DE DADOS}

A metodologia utilizada neste estudo, para a construção do banco de dados ${ }^{2}$ relativos aos casos fatais de acidentes do trabalho, adotou a técnica de vinculação entre duas fontes de dados: os processos de acidentes do trabalho do INSS e as declarações de óbito enviadas pelos Cartórios à Fundação Seade. Desta forma, foi possível identificar e quantificar estes acidentes, caracterizá-los demográfica e epidemiologicamente e mensurar a respectiva mortalidade.

Esta técnica pressupõe a existência de informações individualizadas e uma busca ativa de todos os casos fatais registrados em cada fonte, formando pares com os casos coincidentes. O procedimento permite complementar as informações disponíveis em cada fonte - enriquecendo o detalhamento dos dados coletados e ampliando o universo de casos fatais -, bem como identificar aqueles casos que, apesar de terem sido notificados pelo médico como acidente do trabalho na declaração de óbito, não resultaram em um processo aberto junto ao INSS.

A metodologia de coleta dos dados procurou maximizar a utilização dos registros administrativos existentes, tendo sido realizada uma busca ativa dos casos fatais de aci- 
dentes do trabalho ocorridos em 1991 e 1992, relativos aos residentes no Município de São Paulo.

$\mathrm{Na}$ primeira etapa de desenvolvimento desta técnica, foi elaborada uma pesquisa junto às dez agências do INSS do Município de São Paulo. Foi realizado um levantamento, nos autos dos processos de acidentes do trabalho, dos casos fatais ocorridos no período de referência. A partir dos casos fatais identificados no INSS, foram localizadas as respectivas declarações de óbito no acervo de documentos demográficos da Fundação Seade. Os pares resultantes deste levantamento compuseram um primeiro subconjunto de dados, que correspondem à população trabalhadora coberta pelo INSS.

A segunda fase de aplicação da técnica de vinculação entre fontes de dados consistiu no levantamento de todas as declarações de óbito de 1991 e 1992, existentes no acervo da Fundação Seade, que apresentavam o campo correspondente à notificação de acidente do trabalho assinalado com sim. A seguir, foram localizados os casos correspondentes junto aos processos de acidentes do trabalho, coletados no INSS, e constituídos novos pares. Os casos fatais que, apesar de apresentarem declarações de óbito relativas a um acidente do trabalho devidamente notificado, não corresponderam a um processo de acidente do trabalho junto ao INSS formaram um segundo subconjunto de dados, que se referem, de um modo geral, à população trabalhadora não coberta pelo INSS, ou àqueles contribuintes que não têm dependentes aptos a requererem um benefício junto ao INSS.

O banco de dados de acidentes do trabalho fatais foi composto, então, por dois subconjuntos de informações: no primeiro, encontram-se 569 casos fatais, dos quais 198 foram corretamente notificados nas declarações de óbito; e, no segundo, estão 364 casos devidamente notificados, totalizando, no período 1991-92, 933 mortes por acidentes do trabalho no Município de São Paulo.

\section{CARACTERÍSTICAS DEMOGRÁFICAS E EPIDEMIOLÓGICAS DA POPULAÇÃO ACIDENTADA}

Os dois subconjuntos de dados que compõem o banco de casos fatais de acidentes do trabalho representam parcelas distintas da população trabalhadora residente no Município de São Paulo.

A vinculação entre as duas fontes de registros administrativos é uma alternativa para dimensionar os acidentes fatais relativos à parcela da população não coberta pelo
INSS e não captada por esta fonte, revelando os diferentes perfis demográficos e epidemiológicos das duas parcelas da população acidentada - contribuinte e não contribuinte do INSS.

\section{Casos Fatais Segundo Sexo, Idade e Estado Civil dos Trabalhadores}

A proporção de trabalhadores do sexo masculino que morreram em decorrência de um acidente do trabalho é $93 \%$ superior àquela do sexo feminino.

Essa mesma proporção é ligeiramente menor para a população coberta pelo INSS $(92,8 \%)$ do que para a não coberta $(93,4 \%)$.

No total dos casos detectaram-se 13,4 mortes masculinas para cada caso fatal feminino, sendo que esta razão é de 13,4 para a parcela coberta pelo INSS e de 14,2 para a não coberta. Vale lembrar que a razão de sexo, para a PEA ocupada no Município de São Paulo, era 1,63, segundo os dados censitários de 1991 (Fundação IBGE, 1996). O número excessivo de casos fatais de acidentes do trabalho para os homens, quando comparado com a relação masculino/feminino da população trabalhadora, é indicativo do maior risco a que os homens estão expostos no exercício de sua profissão.

A distribuição dessas mortes, por idade, apresentada no Gráfico 1, mostra a predominância dos casos fatais para a população com idade entre 20 e 29 anos não coberta pelo INSS, ficando em um patamar bem superior àquele verificado para esse segmento populacional coberto por este Instituto. A idade média da população acidentada foi de 36 anos para os homens e de 32 anos para as mulheres.

Comparando-se a participação dos casos fatais segundo o estado civil, observa-se uma distribuição bem distinta entre as duas parcelas populacionais: enquanto para a população coberta pelo INSS a maior proporção referese às pessoas casadas, para a parcela não coberta pelo INSS a maior incidência é de solteiros (Tabela 1).

O comportamento diferenciado dos casos fatais de acidentes do trabalho, correspondentes à população trabalhadora não coberta pelo INSS, pode ser atribuído, em certa medida, ao fato de serem trabalhadores em sua maioria jovens e solteiros. Segundo o Censo Demográfico de 1991 (Fundação IBGE, 1996), 32,1\% dos trabalhadores ocupados tinham entre 20 e 29 anos e, desta parcela, 57,9\% eram solteiros. É possível, para este segmento da população ocupada, considerar a hipótese de inexistência de dependentes aptos à concessão de benefícios do INSS, ou 


\section{GRÁFICO 1}

Óbitos por Acidentes do Trabalho, segundo Faixa Etária

Município de São Paulo - 1991/1992

População Coberta pelo INSS $\quad$..... População Não Coberta pelo INSS $\quad$ Totalidade dos Casos

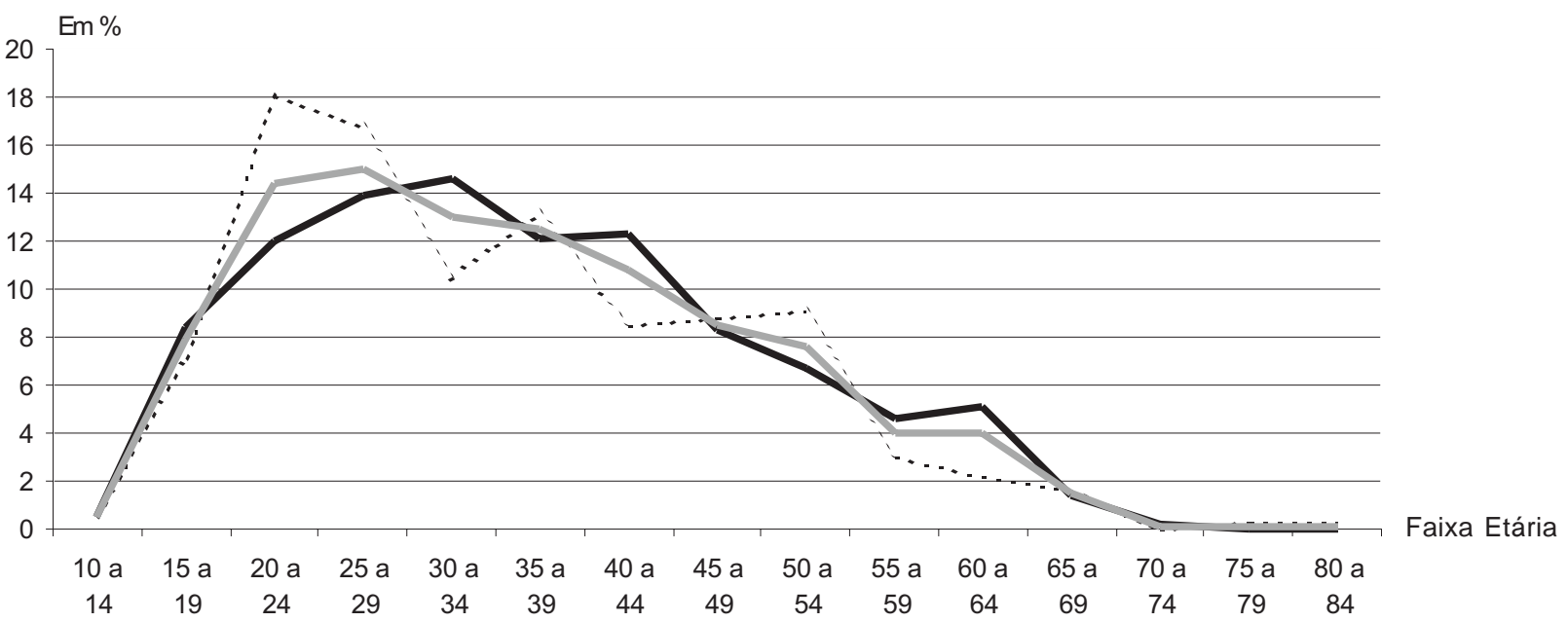

Fonte: Fundação Seade; INSS.

TABELA 1

Óbitos por Acidentes do Trabalho, segundo Estado Civil

Município de São Paulo - 1991/1992

\begin{tabular}{|c|c|c|c|c|c|c|}
\hline \multirow{2}{*}{ Estado Civil } & \multicolumn{2}{|c|}{ População Coberta pelo INSS } & \multicolumn{2}{|c|}{ População Não Coberta pelo INSS } & \multicolumn{2}{|c|}{ Totalidade dos Casos } \\
\hline & Números Absolutos & $\%$ & Números Absolutos & $\%$ & Números Absolutos & $\%$ \\
\hline Total & 569 & 100,0 & 364 & 100,0 & 933 & 100,0 \\
\hline Solteiro & 198 & 34,8 & 176 & 48,4 & 374 & 40,1 \\
\hline Casado & 333 & 58,5 & 156 & 42,9 & 489 & 52,4 \\
\hline Viúvo & 8 & 1,4 & 10 & 2,8 & 18 & 1,9 \\
\hline Divorciado & 15 & 2,6 & 14 & 3,9 & 29 & 3,1 \\
\hline Outros & 15 & 2,6 & 8 & 2,2 & 23 & 2,5 \\
\hline
\end{tabular}

Fonte: Fundação Seade; INSS.

de residência fora dos limites do Estado de São Paulo, quando os dependentes forem os pais. A este fato podese acrescentar, também, a ocorrência de não contribuintes dentre os trabalhadores jovens, estimada em cerca de $20 \%$ segundo o referido Censo.

Mais uma vez ficam em evidência as diferenças detectadas entre as duas parcelas da população trabalhadora: a coberta e a não coberta pelo INSS, resultando em um comportamento também distinto para a totalidade dos casos fatais identificados.

\section{Casos Fatais Segundo a Classificação em Acidente-Tipo e de Trajeto}

A informação sobre o momento do acidente, que permite classificar os acidentes do trabalho em tipo e de trajeto, só está disponível no primeiro subconjunto de dados, relativos aos processos de acidentes do trabalho do INSS. Observa-se que 54,7\% dos casos fatais referem-se a acidentes-tipo. Destes, $52,4 \%$ ocorreram na via pública e $43,4 \%$ na empresa. 
A maior participação dos acidentes-tipo ocorridos na via pública é indicativo da transferência do local de trabalho das atividades profissionais exercidas em serviços urbanos, que passam a ser realizadas fora da empresa, acrescentando, aos riscos inerentes aos processos produtivos, a violência urbana.

Por outro lado, ainda é importante a participação dos acidentes fatais ocorridos dentro da empresa, com efeitos devastadores para a organização empresarial, os colegas e a família do trabalhador acidentado, como lembra Lee (1995). Neste sentido, é relevante conhecer o detalhamento dos tipos de morte mais freqüentes ocorridos para os acidentes-tipo, segundo o local do acidente.

Dos casos fatais de acidentes-tipo ocorridos em via pública, $74,8 \%$ referem-se a veículos a motor e a atropelamentos. Vale ressaltar que, dentre estas mortes, 60,5\% correspondem a condutores de automóveis, ônibus e caminhões. Esta categoria profissional exerce sua ocupação habitual no espaço da rua, estando constantemente exposta aos riscos de acidentes de transporte.

Por outro lado, os homicídios ocupam a primeira posição dentre os acidentes-tipo ocorridos na empresa, com $36,3 \%$. A principal categoria profissional envolvida nestes acidentes é constituída pelos guardas de segurança e assemelhados, respondendo por $57,1 \%$ destes casos. Para esta categoria específica, $67,9 \%$ dos casos fatais ocorridos na empresa decorreram de um latrocínio. É interessante observar, também, que os homicídios superaram aqueles tipos de morte tradicionalmente mais esperados, relativos às atividades profissionais exercidas pelos trabalhadores nas empresas, como as quedas, os choques, as explosões e os esmagamentos, por exemplo.

Mais uma vez, a violência urbana crescente nas grandes cidades atinge o trabalhador no exercício de sua profissão. Os dados de óbitos para a população em geral do Município de São Paulo (Fundação Seade, 1999) apontam o aumento na taxa de mortalidade por homicídios entre 1980 e 1999, que passou de 17,2 óbitos por cem mil habitantes para 66,9 , ou seja, um crescimento médio anual de $7 \%$, nestes 20 anos.

No Município de São Paulo, o segundo tipo de morte mais frequiente, dentre os acidentes-tipo ocorridos na empresa, correspondeu às quedas, sendo os trabalhadores ligados à construção civil os mais atingidos, com 44,7\% dos casos fatais. Em terceiro lugar apareceram os choques, explosões e esmagamentos, em que os trabalhadores ligados às atividades da indústria responderam por $39,4 \%$ dos casos e aqueles pertencentes à construção civil, por $30,3 \%$ dos casos.

\section{Casos Fatais Segundo Tipos de Morte e Grupos Ocupacionais}

O conhecimento dos principais tipos de morte associados aos acidentes do trabalho, assim como dos grupos de ocupação do trabalhador, constitui elemento fundamental para as questões relativas à segurança do trabalho. Estas duas variáveis estão disponíveis nos dois subconjuntos de dados utilizados neste estudo.

Os acidentes do trabalho fazem parte do grupo de causas externas de morte. Segundo a Nona Classificação Internacional de Doenças (OMS, 1985), que era a classificação vigente no período de referência deste estudo, encontram-se nesta seção os eventos ambientais, circunstanciais e condições consideradas como causa da lesão, envenenamento ou outros efeitos adversos que levem um indivíduo à morte. Este grupo de causas representava 22,1\% do total dos óbitos ocorridos na população em idade ativa, no Município de São Paulo, entre 1991 e 1992.

A participação das causas externas no total de óbitos da população em idade ativa, de ambos os sexos, foi bem distinta: enquanto para as mulheres estas causas representavam apenas $8,7 \%$ do total de óbitos, para os homens alcançavam $23,3 \%$. A razão entre os sexos era de 7,0 mortes masculinas por causas externas para cada morte feminina. Os acidentes do trabalho fatais, para a totalidade da população trabalhadora residente no Município de São Paulo, representavam 5,9\% do total dos óbitos por causas externas, na população em idade ativa, sendo $6,2 \%$ para os homens e $3,3 \%$ para as mulheres.

Outro aspecto importante é conhecer o quanto estes acidentes contribuem na mortalidade por causas externas da população em idade ativa, o que pode ser avaliado na Tabela 2.

Sobressai o peso dos atropelamentos caracterizados como acidente do trabalho (14\%), em relação às ocorrências correspondentes ao total da população em idade ativa. É relevante, também, a participação dos acidentes com veículo a motor. Os demais tipos de morte mais detalhados não são discriminados, devido à sua pequena representatividade.

A distribuição dos casos fatais por tipo de morte, para a população coberta e não coberta pelo INSS, apresenta diferenças importantes.

Para os casos cobertos pelo INSS, os acidentes com veículo a motor apareceram em primeiro lugar como acidente do trabalho (33,6\%); seguidos pelos homicídios 
$(22,0 \%)$ e atropelamentos $(17,2 \%)$. Quanto à população acidentada não apreendida pelo INSS, os homicídios representaram grande parcela dos casos fatais $(38,5 \%)$, bem superior à participação relativa observada na outra parcela populacional. Em segundo lugar, vêm os atropelamentos $(20,9 \%)$. Destacam-se também as quedas, com $12,6 \%$ dos casos, e os acidentes com veículo a motor, com $10,7 \%$.

Quando se considera o conjunto da população trabalhadora, a composição relativa de cada tipo de morte se altera. Os homicídios detêm a maior participação $(28,4 \%)$, seguidos pelos acidentes com veículo a motor $(24,7 \%)$ e atropelamentos $(18,6 \%)$.

Constata-se, novamente, que os tipos de morte mais freqüentes como acidentes do trabalho são os ocorridos no espaço público, e não aqueles característicos das diversas atividades profissionais tradicionalmente mais expostos aos riscos de acidentes. Este resultado tem implicações diretas nas estratégias e medidas de segurança ocupacional, extrapolando para toda a sociedade e para o poder público, em geral, o planejamento de ações mais globais que atuem na segurança das condições urbanas mais amplas.

Cruzando-se as variáveis grupos ocupacionais com tipos de morte, observam-se algumas diferenças importantes nas distribuições resultantes para as duas parcelas populacionais estudadas (Tabela 3 ).

Verifica-se que o mesmo cruzamento apareceu em primeiro lugar. Um em cada cinco casos fatais de acidentes do trabalho, identificados na parcela não coberta pelo INSS, correspondeu ao grupo de ocupações ligadas ao serviço e comércio, tendo o homicídio como principal tipo de morte. Para a parcela coberta, este cruzamento respondeu por $14,1 \%$ dos casos.

Outro ponto que sobressai é o fato de o grupo de ocupações ligadas à construção civil aparecer quatro vezes entre os sete principais cruzamentos, na população não contribuinte, concentrando $20,9 \%$ destes casos fatais. $\mathrm{Na}$ primeira parcela, este grupo de ocupações só apareceu uma vez, respondendo por 5,3\% dos casos fatais de maior ocorrência de acidentes do trabalho. Agregando-se as duas parcelas populacionais, destaca-se o grupo de serviço e comércio nas três primeiras posições.

As análises decorrentes das associações, entre o grupo de ocupação e o tipo de morte, permitem concluir que a ocorrência de acidentes do trabalho difere bastante entre as duas parcelas da população trabalhadora residente no Município de São Paulo.
TABELA 2

Participação dos Óbitos por Acidentes do Trabalho no Total de Óbitos por Causas Externas, para a População em Idade Ativa (1), segundo os Tipos de Morte Município de São Paulo - 1991/1992

Em porcentagem

\begin{tabular}{lccc}
\hline \multirow{2}{*}{$\begin{array}{l}\text { Tipos de } \\
\text { Morte }\end{array}$} & \multicolumn{3}{c}{ Participação da PIA (1) } \\
\cline { 2 - 4 } & Homens & Mulheres & Total \\
\hline Total & $\mathbf{6 , 2}$ & 3,3 & $\mathbf{5 , 9}$ \\
Acidente com Veículo a Motor & 12 & 4,6 & 10,6 \\
Atropelamento & 16,4 & 6,7 & 14,1 \\
Demais Acidentes & 7,4 & 2,8 & 6,7 \\
Homicídio & 3,4 & 2 & 3,3 \\
\hline
\end{tabular}

Fonte: Fundação Seade; INSS.

(1) Foi considerada como idade ativa a população entre 15 e 69 anos.

TABELA 3

Óbitos por Acidentes do Trabalho, segundo Grupos Ocupacionais Município de São Paulo - 1991/1992

Grupos Ocupacionais $\%$

População Coberta pelo INSS

Serviço e Comércio X Homicídio

14,06

Transporte e Comunicação X Demais Acidentes de Trânsito $\quad 10,72$

Serviço e Comércio X Demais Acidentes de Trânsito $\quad 10,37$

Serviço e Comércio X Atropelamento $\quad 7,91$

Construção Civil X Outros $\quad 5,27$

Transporte e Comunicação X Homicídio 4,22

Indústria X Demais Acidentes de Trânsito 4,22

População Não Coberta pelo INSS

Serviço e Comércio X Homicídio

20,60

Serviço e Comércio X Atropelamento

7,42

Construção Civil X Atropelamento

6,32

Construção Civil X Outros

6,04

Transporte e Comunicação X Homicídio $\quad 5,77$

Construção Civil X Homicídio $\quad 4,40$

Construção Civil X Queda $\quad 4,12$

Totalidade dos Casos

Serviço e Comércio X Homicídio $\quad 16,61$

Serviço e Comércio X Atropelamento $\quad 7,72$

Serviço e Comércio X Demais Acidentes de Trânsito 7,61

Transporte e Comunicação X Demais Acidentes de Trânsito $\quad 7,50$

Construção Civil X Outros $\quad 5,57$

Transporte e Comunicação X Homicídio 4,82

Construção Civil X Atropelamento $\quad 4,29$

Fonte: Fundação Seade; Fundação IBGE; INSS 


\section{MORTALIDADE POR ACIDENTES DO TRABALHO}

A análise da mortalidade por acidentes do trabalho revela as marcantes diferenças do risco de morrer no exercício cotidiano do trabalho entre as duas parcelas da população trabalhadora aqui consideradas: a coberta e a não coberta pelo INSS. Estes diferenciais foram avaliados segundo o sexo, a idade, o estado civil e o grupo ocupacional.

Os coeficientes foram calculados para as pessoas em idade ativa, aqui considerada entre 15 e 69 anos, uma vez que $97,2 \%$ do total dos casos fatais ocorreram neste grupo etário.

A população adotada como denominador dos coeficientes específicos de mortalidade foi aquela recenseada em 1991, pela Fundação IBGE, que levantou a população residente, a ocupada e aquela ocupada e contribuinte do INSS, segundo os diversos atributos considerados neste estudo.

No Município de São Paulo, 62,3\% da população residente estava ocupada, sendo que, deste contingente populacional, 78,4\% eram contribuintes de Institutos de Previdência Pública. A proporção de homens ocupados era bem superior à de mulheres: 80,8\% e 45,4\%, respectivamente. Por outro lado, a participação dos ocupados que também são contribuintes não difere tanto entre os gêneros: $80,5 \%$ para os homens e 75,0\% para as mulheres.

Para o cálculo dos coeficientes de mortalidade, a parcela populacional que serviu de denominador para o primeiro subconjunto de dados, em que os casos fatais de acidentes do trabalho foram identificados a partir dos processos do INSS, foi a população ocupada e contribuinte. Para o segundo subconjunto de dados, em que os casos fatais foram identificados pelas declarações de óbito notificadas e não selecionadas nos processos do INSS, o denominador foi a população ocupada e não contribuinte.

A primeira dimensão a ser analisada é a mortalidade por sexo. Observa-se que os coeficientes de mortalidade masculina por acidentes do trabalho foram sempre bem superiores à feminina, cerca de oito vezes mais. Para o total da população masculina ocupada, os coeficientes foram 16,9 óbitos por cem mil e, para as mulheres, 2,1.

Quando se comparam os riscos de morte aproximados pelos coeficientes de mortalidade, para as duas parcelas da população, verificam-se diferenciais muito importantes. Para a população masculina não coberta pelo INSS, a mortalidade por acidentes do trabalho foi 2,6 vezes superior àquela registrada para a parcela coberta por este Instituto. Este resultado revela a situação problemática das famílias não cobertas pelo INSS, que ficam desamparadas quando ocorre uma morte por acidente do trabalho.

A segunda dimensão da análise da mortalidade por acidente do trabalho é a idade. O Gráfico 2 apresenta as curvas descritas pelos coeficientes dos óbitos por idade, para a população masculina. Não foi possível realizar o mesmo procedimento em relação às mulheres, devido ao número muito reduzido de casos fatais identificados.

A tendência, de um modo geral, foi crescente com a idade, ficando os coeficientes relativos à população não contribuinte em um patamar bem superior àqueles verificados para a população ocupada e contribuinte.

Para a população não coberta pelo INSS, o maior coeficiente de mortalidade foi registrado nas idades entre 50 e 54 anos, quando alcançou o valor de 57,9 óbitos por acidentes do trabalho para cada cem mil trabalhadores não contribuintes. Os ocupados não contribuintes com 20 a 29 anos e com 35 a 39 anos também apresentaram altas taxas de mortalidade, próximas de 40 óbitos por cem mil. Nestes grupos etários, os riscos de morte foram mais que 3,6 vezes superiores aos correspondentes à população coberta pelo INSS.

Para a totalidade dos casos, observa-se um aumento da mortalidade por acidentes do trabalho com o avançar da idade da população trabalhadora. Para os ocupados com idades entre 60 e 69 anos, 56\% dos casos fatais foram acidentes-tipo e $44 \%$ de trajeto. Os tipos de morte mais freqüentes estiveram relacionados com acidentes ocorridos no espaço da rua, sendo que $36 \%$ corresponderam a atropelamentos e $30 \%$ a acidentes com veículo a motor. Ressalta-se que, para a população em geral, crescem com a idade as taxas de mortalidade decorrentes de um atropelamento, vitimando de modo expressivo a população mais idosa.

Além disso, o envelhecimento humano afeta os sistemas vitais e, com a diminuição gradativa de sua eficácia, que leva a uma perda da habilidade funcional, é possível ocorrer um desequilíbrio na relação entre capacidade e demandas do trabalho.

A terceira dimensão é o estado civil do trabalhador. Para a população ocupada e contribuinte, observa-se um maior coeficiente de mortalidade por acidentes do trabalho para os homens casados do que para os solteiros (Tabela 4).

Entretanto, quando se estimam os coeficientes de mortalidade tanto para os trabalhadores não cobertos quanto para a totalidade dos casos, estes diferenciais quase desaparecem, e o estado civil passa a não ser mais um atributo populacional de distinção entre as populações acidentadas. 


\section{GRÁFICO 2}

Óbitos por Acidentes do Trabalho da População Masculina, segundo Faixa Etária

Município de São Paulo - 1991/1992

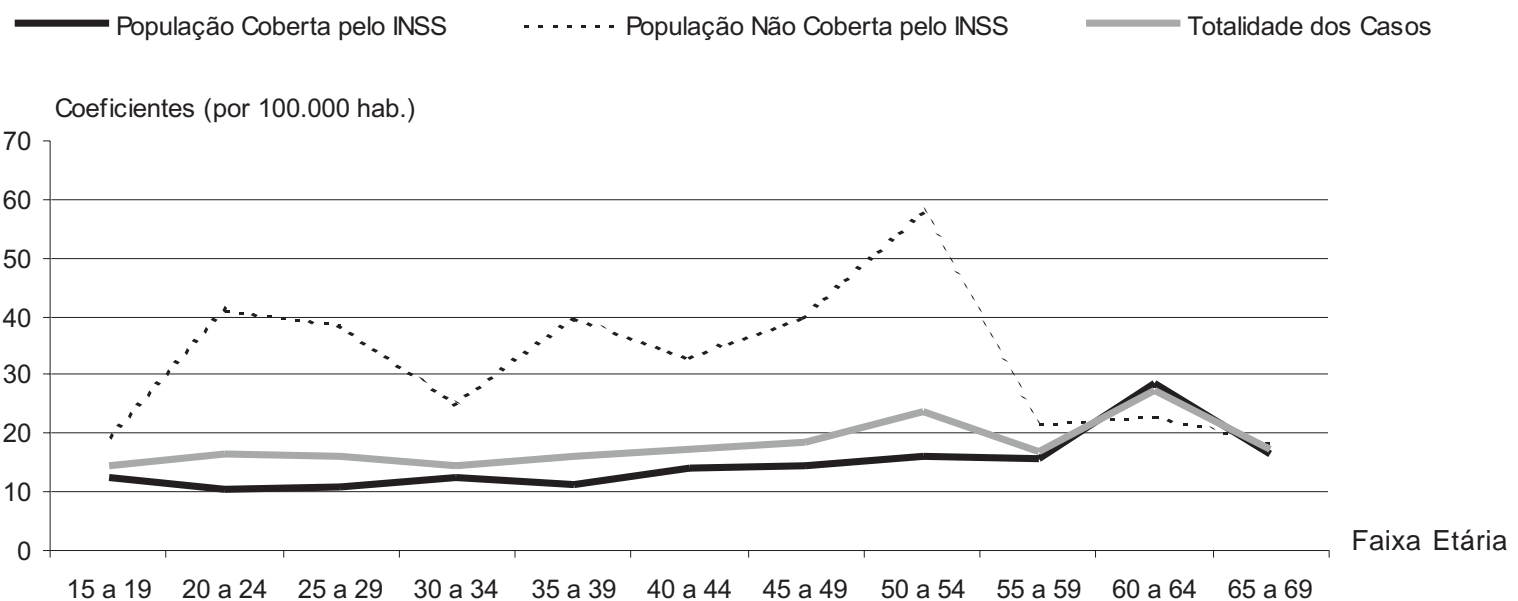

Fonte: Fundação Seade; Fundação IBGE; INSS.

Vale ressaltar, mais uma vez, que o nível da mortalidade para a parcela não coberta pelo INSS é bem superior ao da parcela coberta, sendo que para os solteiros esta relação é três vezes maior e, para os casados, 1,8 vez.

A quarta dimensão deste estudo refere-se à mortalidade segundo a ocupação do trabalhador. Para as mulheres trabalhadoras residentes no Município de São Paulo, os maiores coeficientes de mortalidade foram registrados no grupo ocupacional ligado ao transporte e comunicação, com 9,51 óbitos por cem mil ocupadas e contribuintes. Em seguida, vêm os grupos ligados ao serviço e comércio, com 3,38 óbitos por cem mil, e aqueles relativos à indústria e à construção civil, com 3,21 óbitos por cem mil. Os coeficientes de mortalidade verificados para as trabalhadoras contribuintes não diferem muito das não contribuintes, com exceção do grupo ocupacional ligado a transporte e comunicação no qual, para esta última parcela populacional, o coeficiente foi nulo.

Quanto ao total da população masculina ocupada, os mesmos três grupos ocupacionais surgem como os detentores dos maiores coeficientes de mortalidade, mas com ordens de grandezas bem superiores, cerca de oito vezes maiores que os estimados para as mulheres. O grupo ocupacional masculino com patamares superiores de risco de ocorrência de um acidente do trabalho fatal foi aquele ligado às atividades de transporte e comunicação, com coeficientes de 41,14 óbitos por cem mil trabalhadores ocupados, em que os condutores de automóveis, ônibus e caminhões detêm a maior

TABELA 4

Óbitos por Acidente do Trabalho da População em Idade Ativa, por Estado Civil, segundo Sexo Município de São Paulo - 1991/1992

\begin{tabular}{|c|c|c|c|c|c|c|}
\hline \multirow{2}{*}{ Sexo } & \multicolumn{2}{|c|}{ População Coberta pelo INSS } & \multicolumn{2}{|c|}{ População Não Coberta pelo INSS } & \multicolumn{2}{|c|}{ Totalidade dos Casos } \\
\hline & Solteiro & Casado & Solteiro & Casado & Solteiro & Casado \\
\hline Total & 6,61 & 10,50 & 19,61 & 19,14 & 9,64 & 12,32 \\
\hline Homem & 10,50 & 13,65 & 31,88 & 32,24 & 15,50 & 16,75 \\
\hline Mulher & 1,42 & 2,08 & 3,03 & 2,35 & 1,71 & 2,15 \\
\hline
\end{tabular}

Fonte: Fundação Seade; Fundação IBGE; INSS. 
participação relativa. Seguem os grupos ocupacionais ligados ao serviço e ao comércio, com 29,84 óbitos por cem mil, e aqueles pertencentes à indústria e à construção civil, com 20,34 óbitos por cem mil.

Comparando-se os coeficientes de mortalidade masculina para as duas parcelas da população (Gráfico 3), observa-se que a ordenação dos grupos populacionais foi a mesma, mas a ordem de grandeza dos coeficientes foi sempre superior para os ocupados não cobertos pelo INSS.

Chama a atenção o nível da mortalidade registrado no grupo de transporte e comunicação, que alcança 76,75 óbitos por acidentes do trabalho por cem mil trabalhadores não cobertos pelo INSS.

Para todas as comparações realizadas, os coeficientes de mortalidade relativos à população não coberta pelo INSS superaram aqueles correspondentes à população contribuinte deste órgão.

Evidentemente, os casos fatais identificados como relativos à população não contribuinte não correspondem à cobertura total de casos ocorridos para esta parcela da população. Na verdade, o respectivo subconjunto de dados é composto apenas pelas mortes que foram notificadas como acidentes do trabalho nas declarações de óbito, ficando excluídos os casos não notificados. Estes últimos não fazem parte de nenhuma fonte de dados, sendo dificilmente captados em uma pesquisa amostral.
Por outro lado, também existe uma parte dos casos fatais identificados no segundo subconjunto de dados que podem corresponder a trabalhadores contribuintes do INSS, mas sem dependentes aptos a requererem o benefício junto a este Instituto. Acredita-se, entretanto, que esta participação seja reduzida.

Trabalhou-se, portanto, com a hipótese de que os casos fatais levantados seriam uma aproximação dos acidentes do trabalho relativos à parcela populacional não coberta pelos institutos de previdência. Apesar das limitações existentes, os coeficientes de mortalidade por acidentes do trabalho, assim produzidos, representam uma estimativa dos riscos de morte da população trabalhadora não coberta pelo INSS e podem ser úteis para a análise da questão acidentária.

\section{CONSIDERAÇÕES FINAIS}

A vinculação entre as duas fontes de dados consideradas neste estudo - processos de acidentes do trabalho e declarações de óbito - mostrou-se um importante instrumento para o estudo dos casos fatais de acidentes do trabalho. Este procedimento metodológico possibilitou a identificação dos casos fatais da população coberta e também daquela não coberta pelo INSS. O banco de dados, resultante desta vinculação de fontes de registros admi-

\section{GRÁFICO 3}

Óbitos por Acidentes de Trabalho da População Masculina, segundo Grupos Ocupacionais

Município de São Paulo - 1991/1992

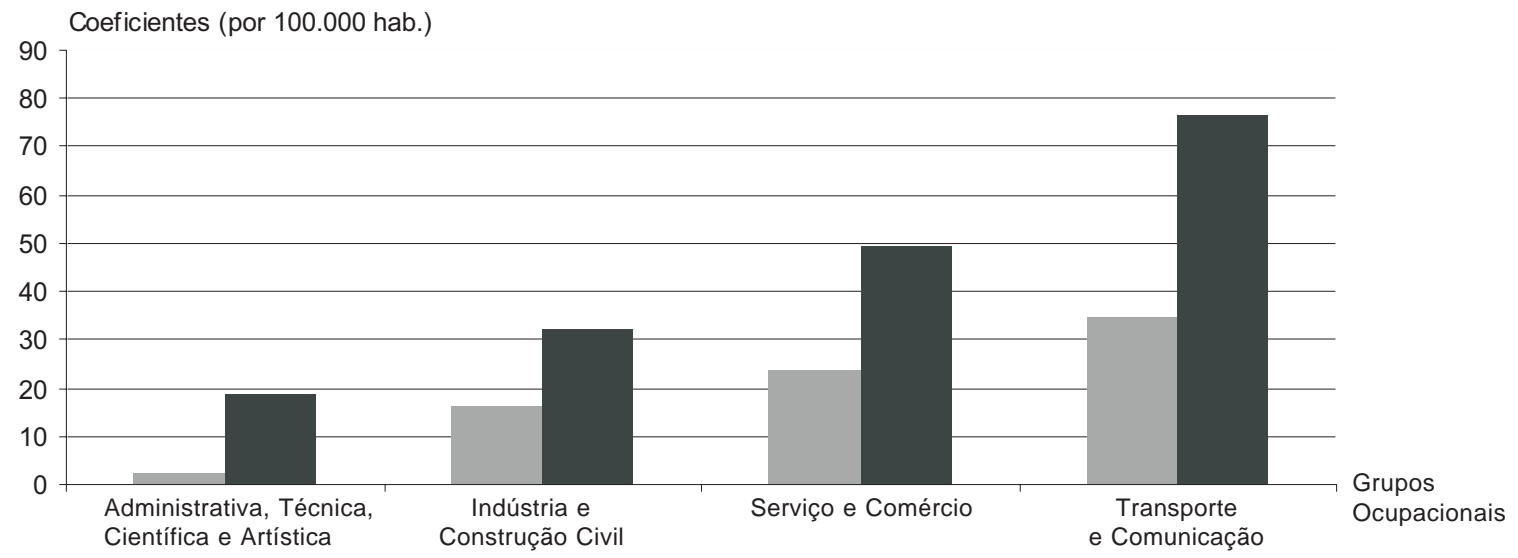

Fonte: Fundação Seade; Fundação IBGE; INSS. 
nistrativos, representa um valioso material para as análises das ocorrências de acidentes do trabalho que levam à consequiência mais grave na saúde do trabalhador, que é a perda de sua vida.

A identificação das populações expostas ao risco destes acidentes fatais, segundo o sexo, a idade, o estado civil e a ocupação permite a estimativa dos coeficientes específicos de mortalidade e dos diferenciais de graus de riscos. Esta informação é útil, também, para nortear as políticas e as medidas que visem a diminuição destas mortes.

É importante ressaltar que este fenômeno é muito difícil de ser captado em uma pesquisa amostral. Desta forma, a metodologia proposta para a coleta dos casos fatais, a organização do banco de dados, a construção e a análise dos indicadores constituem uma alternativa viável e factível de renovação periódica, representando, ao mesmo tempo, uma atividade de baixo custo monetário, e de alto benefício social. Este tipo de estudo pode fornecer relevantes subsídios para o entendimento da questão acidentária e para a orientação de políticas e medidas de segurança no trabalho, visando minimizar ou reduzir os riscos a que os trabalhadores estão expostos no exercício cotidiano de sua profissão.

Uma constatação relevante detectada neste trabalho é a de que os casos fatais de acidentes do trabalho tipo não estão mais associados apenas às atividades realizadas dentro do ambiente de trabalho, restrito às empresas, assim como os tipos de morte mais freqüentes não são mais aqueles relacionados diretamente com os processos intrínsecos ao trabalho. Os principais cruzamentos, entre os grupos ocupacionais e os tipos de morte, apresentaram uma importante participação daqueles riscos mais gerais associados ao total da população, independentemente de sua condição de trabalho.

Os homicídios apareceram, junto com os acidentes com veículos a motor e os atropelamentos, como os principais tipos de morte relativos aos acidentes do trabalho, sinalizando a expansão do local do trabalho para o espaço da rua. Este fato aumenta os riscos potenciais de acidentes do trabalho, em consequiência da violência crescente nos centros urbanos, do trânsito caótico das grandes cidades e rodovias, além da má conservação dos veículos que nelas circulam, acrescentando estes riscos àqueles inerentes aos processos de trabalho.

Outra constatação importante é o diferencial de risco de morte por acidente do trabalho observado para as duas parcelas da população trabalhadora: a coberta e a não coberta pelo INSS, sendo esta última detentora dos maiores riscos de acidentes fatais no exercício do trabalho.

Estas reflexões inserem a questão dos acidentes do trabalho fatais dentro de um contexto maior de convulsão social, em que as medidas mais tradicionais de segurança no trabalho não são suficientes para prevenir ou reduzir estes acidentes fatais.

A integração dos órgãos produtores de estatísticas relativas aos acidentes do trabalho, procurando vincular as informações específicas de cada registro administrativo, constitui um valioso instrumento na questão acidentária. Esta vinculação amplia o potencial de análise e permite identificar os diferentes perfis demográficos e epidemiológicos da população acidentada, coberta e não coberta pelo INSS, e da população exposta aos riscos fatais de um acidente do trabalho.

\section{NOTAS}

E-mail da autora: bvogel@ seade.gov.br

Colaborou na elaboração deste estudo Daniel Waldvogel Thomé da Silva.

1. Um processo é considerado "liquidado" quando a sua avaliação se encerra administrativa e tecnicamente (Empresa de Processamento de Dados da Previdência Social, 1994)

2. O banco de dados considerado neste estudo foi constituído na elaboração do trabalho de Waldvogel (1999).

\section{REFERÊNCIAS BIBLIOGRÁFICAS}

ALVES, S. e LUCHESI, G. "Acidentes do trabalho e doenças profissionais no Brasil. A precariedade das informações." Informe Epidemiológico do SUS, v.1, n.13, 1992, p.7-19.

BELLUSCI, S.M. e FISCHER, F.M. "Envelhecimento funcional e condições de trabalho em servidores forenses." Revista da Saúde Pública. São Paulo, dez. 1999 (no prelo).

CAMARGO, A.B.M. “A mortalidade por acidentes de transporte em São Paulo." Informe Demográfico GEPOP. São Paulo, n.2, 1999, p.1-9.

CASTILHO D.N. e JENKINS, E.L. "Industries and occupations at high risk for work - related homicides." Journal Occupa. Med, v.36, n.2, fev. 1994, p.125132.

EMPRESA DE PROCESSAMENTO DE DADOS DA PREVIDÊNCIA SOCIAL. "Indicadores sociais: benefícios concedidos e acidentes de trabalho registrados e liquidados." Previdência em Dados, v.9, n.2, abr.-jun. 1994, p.45-68.

FERREIRA C.E.C. e CASTIÑEIRAS L.L. "O rápido aumento da mortalidade dos jovens adultos em São Paulo: uma trágica tendência.” São Paulo em Perspectiva. São Paulo, Fundação Seade, v.10, n.2, abr.-jun. 1996, p.34-41.

FUNDAÇÃO IBGE. Censo Demográfico de 1991: resultados definitivos. São Paulo. Rio de Janeiro, 1996 (CD-ROM com os microdados da amostra).

FUNDAÇÃO SEADE e FUNDACENTRO. Relatório final do convênio: Mortalidade por Acidentes do Trabalho. São Paulo, 1994.

FUNDAÇÃO SEADE. Sistema de Mortalidade por Causas, 1991 e 1992. São Paulo, 1999 (disquetes - versão 1999). Sistema de População. São Paulo, 1999 (disquetes - versão 1999). 
Sistema de Estatísticas Vitais. São Paulo, 1991 e 1992 (base de dados eletrônica)

GAWRYSZEWSKI, M. et alli. Acidentes do trabalho fatais. (Estudo sobre acidentes do trabalho fatais no Estado de São Paulo no ano de 1995). Ministério do Trabalho e Emprego, Delegacia Regional do Trabalho no Estado de São Paulo, dez. 1998.

LEE, G. "Death in the workplace." AAOHN Journal, v.43, n.2, mar. 1995, p.122.

LUCCA, S.R. e MENDES, R. "Epidemiologia dos acidentes do trabalho fatais em área metropolitana da região sudeste do Brasil." Revista de Saúde Pública, v.27, n.3, jun. 1993, p.168-76.

MACHADO, J.M.H. e GOMEZ, C.M. “Acidentes de trabalho: concepções e dados.” In: MINAYO, M.C.S. (org.). Os muitos Brasis: saúde e população na década de 80. São Paulo/Rio de Janeiro, Hucitac-Abrasco, 1995, p.117142.
ORGANIZAÇÃO MUNDIAL DA SAÚDE. CBCD. $9 \stackrel{a}{a}$ Revisão da Classificação de Doenças, 1985.

SEGRE, M. "Breve resumo da legislação da prática médica dos acidentes do trabalho." Revista Brasileira de Saúde Ocupacional, v. 13, n. 50, abr.-jun. 1985, p.50-62.

WALDVOGEL, B.C. "Mortes precoces de trabalhadores em São Paulo." São Paulo em Perspectiva. São Paulo, Fundação Seade, v. 7, n. 2, abr.-jun. 1993, p.124132.

. Acidentes do trabalho, os casos fatais: a questão da identificação e da mensuração. Tese de Doutorado, São Paulo, Universidade de São Paulo, dez. 1999

WÜNCH FILHO, V. "Variações e tendências na mortalidade dos trabalhadores." In: MONTEIRO, C.A. (org.). Velhos e novos males da saúde no Brasil. São Paulo, Hucitec/Nupens/USP, 1995, p.289-330. 